


\section{Determination of the irreversible loss rate of amino acids in broilers}

J. van der Meulen, P. van Wikselaar, A.J.M. Jansman

Wageningen Livestock Research

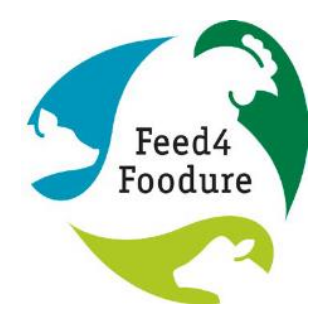

This research was conducted by Wageningen Livestock Research in the framework of the Public Private Partnership 'Breed\&Feed4Food' (AF-14215) and funded by the Ministry of Agriculture, Nature and Food Quality and Vereniging Diervoederonderzoek Nederland (VDN).

Wageningen Livestock Research

Wageningen, May 2019

Report 1169 
J. van der Meulen, P. van Wikselaar, A.J.M. Jansman (2019). Determination of the irreversible loss rate of amino acids in broilers. Report 1169

This report can be downloaded for free at https://doi.org/10.18174/477672 or at www.wur.nl/livestock-research (under Wageningen Livestock Research publications).

(C) 2019 Wageningen Livestock Research

P.O. Box 338, 6700 AH Wageningen, The Netherlands, T +31 (0)317 483953 ,

E info.livestockresearch@wur.nl, www.wur.nl/livestock-research. Wageningen Livestock Research is part of Wageningen University \& Research.

All rights reserved. No part of this publication may be reproduced and/or made public, whether by print, photocopy, microfilm or any other means, without the prior permission of the publisher or author.

Wageningen Livestock Research is NEN-EN-ISO 9001:2015 certified.

All our research commissions are in line with the Terms and Conditions of the Animal Sciences Group. These are filed with the District Court of Zwolle. 


\section{Table of contents}

1

$\begin{array}{ll}\text { Introduction } & \mathbf{5}\end{array}$

2

Materials and methods $\quad 6$

2.1 Experimental design 6

2.2 Surgery 6

$\begin{array}{lll}2.3 & \text { Blood sampling } & 7\end{array}$

$\begin{array}{lll}2.4 & \text { Analysis } & 8\end{array}$

2.5 Calculations $\quad 8$

$3 \quad$ Results $r$

4 Discussion $r$

$5 \quad$ Literature $r$

$\begin{array}{ll}\text { Appendix } 1 & 16\end{array}$ 



\section{Introduction}

Some years ago, the determination of the plasma irreversible loss rate (ILR) was introduced as a method to gain insight into the consequences of immune system activation on amino acid (AA) metabolism in pigs [1]. ILR is the amount of free AA that disappears per unit of time (flux) from the blood plasma pool for protein synthesis or oxidation of $A A$ in organs and tissues. This technique was developed to measure changes of ILR of multiple AA simultaneously in response to immune system activation and differences in health status. ILR includes the use of AA for both protein synthesis and AA oxidation, but does not distinguish between both fluxes. The ILR of AA in plasma in combination with the pool size or concentration of $A A$ in blood plasma is, however, more useful for quantifying changes in AA metabolism than merely changes in plasma AA concentrations or plasma pool sizes. Changes in AA metabolism, e.g. an increased protein synthesis rate, can occur without concomitant changes in plasma AA concentrations or pool size, as AA concentrations can be maintained when fluxes related to protein $(A A)$ intake, breakdown and synthesis of body protein, and oxidation of $A A$ change [2]. The combination of measurements of ILR for AA, whole body $N$ balance and AA pool size can be used to provide insight in metabolic changes in utilization of multiple AA simultaneously. It is hypothesized that e.g. an increase in blood acute-phase proteins (APP) during immune system activation or compromised health status affects the utilisation of AA. With the isotope dilution technique, the pool size and ILR, i.e. the amount of free AA that disappear per unit of time from the plasma pool for protein synthesis or oxidation, can be determined. The ILR is determined by measuring and fitting the change in plasma isotopic enrichment of individual $A A$ in time after intravenous (i.v.) administration of $\mathrm{U}-{ }^{13} \mathrm{C}$-labelled AA. The combined measurements of whole body $\mathrm{N}$ retention, plasma irreversible loss rate urea entry and appearance of ${ }^{13} \mathrm{C}$ into plasma proteins in pigs, provided insight into the consequences of immune system activation on AA metabolism [1].

The aim of the pilot-studies described in the present report was to translate the technique of measuring ILR in growing pigs to broilers. When this technique is operable in broilers, it will be possible to investigate also in broilers the effect of health status on AA metabolism and requirements for body protein deposition and for immune system functioning. Such information is important for optimizing broiler diets in dependence of their health status, and thereby improving overall nutrient utilization and reducing their excretion into the environment. Feeding adjusted diets may also support the broiler's capacity to cope with challenges to the immune system.

In translating the technique of measuring ILR in growing pigs to broilers, however, differences between growing pigs and broilers needed to be taken into account or experienced. In the material and methods described below, the state of art in housing, feeding, surgery, sampling and calculation of results are described, including, in short retrospect, what adjustments needed to be made in a setting with broilers compared to pigs for using the technique of ILR determination for AA. 


\section{Materials and methods}

\section{$2.1 \quad$ Experimental design}

Day-old male broilers (Ross 308 ) were raised in a group (floor pen).

At the start of the study (day 0 ), broiler chickens (age 20 days) were weighed and individually housed in cages $(70 \times 80 \mathrm{~cm}$, height $40 \mathrm{~cm})$ at a room temperature of $220 \mathrm{C}$ and a light period of 20 h (06:00 $\mathrm{h}-02: 00 \mathrm{~h}$ ). Feed and water were available ad lib. After 4 days (at day 5 ) the broilers were surgically fitted with a catheter (for blood sampling and administration of ${ }^{13} \mathrm{C}$-labelled AA) (Figure 1).

The flux of $A A$ was determined after bolus administration of ${ }^{13} \mathrm{C}$-labelled AA one day after surgery and after a period of continuous administration of ${ }^{13} \mathrm{C}$-labelled AA (for $6 \mathrm{~h}$ ) 3 days after surgery. Results on the latter are not reported here.

\section{Feeding}

The one-day old broilers were fed ad lib a standard commercial starter pelleted diet and from 10 days of age a standard commercial grower pelleted diet.

In the first days of the experiment after housing in the individual cages, the birds were fed at lib. On the day before surgery and the day of surgery the broilers were fed smaller portions (4x) during the light period $(08: 00 \mathrm{~h}, 11: 00 \mathrm{~h}, 14: 00 \mathrm{~h}$ and 17:00 $\mathrm{h}$ ) to adapt to the provision of small meals over a day. On the day after surgery when the AA flux was determined, the birds were fed 7 smaller portions (06:00 h, 08:00 h, 10:00 h, 12:00 h, 14:00 h, 16:00 h and 17:00 h) in order to create a steady state of the flux of AA from the gastrointestinal tract (as a result of protein digestion and AA absorption) to the systemic circulation and to create a steady state of $A A$ in the systemic circulation.

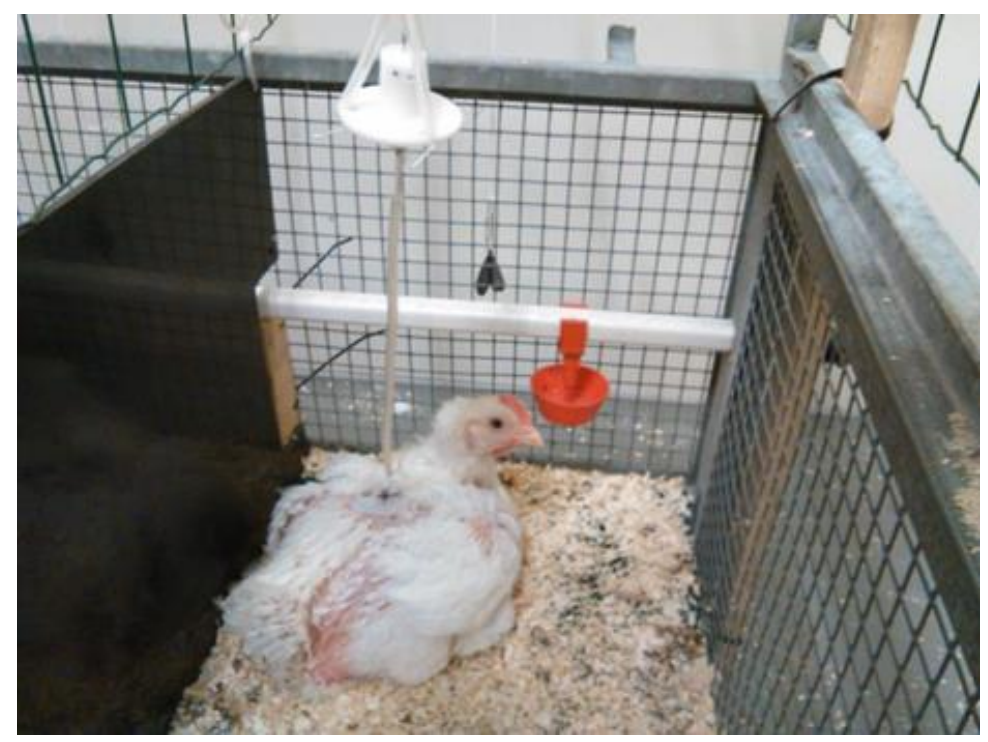

Figure 1 Broiler catheterized in the wing vein used for the determination of the irreversible loss rate of amino acids.

\subsection{Surgery}

The ILR is determined by measuring and mathematical fitting the change in plasma isotopic enrichment of individual $A A$ in time after i.v. administration of $U-{ }^{13} \mathrm{C}$-labelled AA. For the measurement, broiler birds are needed in which labelled AA can be administered intravenously and of 
which multiple blood samples can be taken in a relative short time frame after administration of labelled AA, preferable without stress.

While there is much experience in frequent blood collection in (catheterized) pigs, both within our institute as in literature, there is ample experience in frequent collection of blood in broilers or layers. Coagulation of blood is different in poultry than in pigs and in studies with broilers and layers, blood is taken always almost occasionally.

In fitting (a) catheter(s) into the wing vein of a broiler, filling it with anti-coagulants and placing an extension tube line to the catheters before starting administration and sampling, some critical points were encountered. It appeared that in broilers of less than $1 \mathrm{~kg}$ of body weight, the success rate of successfully implanting one or two catheters in the wing vein was low. Besides, the use of the anticoagulant heparin in the same way as applied in pigs resulted in loss of patency of catheters on the next day. In addition, placing an extension fluid line to the catheter in a wing of a bird, as is needed for frequent sampling, was much more stressful for the bird compared to pigs, in which catheters are fixed on the back. Although the use of higher concentrations of heparin and using a published alternative (heparinised poly vinyl pyrolidone)[3] did improve the functional life time of the catheters to some extent, a permanent infusion of heparinised saline into the catheter not only prevented clotting of blood in the catheter but also omitted the stressful coupling to the extension tube line and ensured sampling without stress to the bird. For this, the catheter was joined to a connecting tube and thereafter joined to a swivel. A swivel serves as a rotary fluid seal and prevents that the bird is significantly encumbered in its movement, and that the fluid line is partially or totally occluded. Another tube was used to join the other end of the swivel to the infusion pump. The swivel used was a standard swivel for research in rats. Unfortunately, jackets (for fixing the catheter to the broiler and joining the connection tube) and a swivel balance arm as used for research in rats, could not be used in a setting with broilers.

Birds were fitted a catheter essentially according de Jong [3]. The bird was taken out of the cage, weighed and fixed on its back on a table in the surgery room. The beak and head were inserted in a mask and anaesthesia was induced $(\sim 3 \%)$ and maintained $(2-3 \%)$ with sevoflurane. The feathers were removed from the site of catheterization under the left wing and the site was swabbed using $70 \%$ ethanol. The sterile catheter (Leadercath2E.L, Vygon) consisted of a 20-gauge needle which was bathed in and filled with heparin. The introducer needle was brought $0.5 \mathrm{~cm}$ proximal into the vena cutanea ulnaris at $2 \mathrm{~cm}$ distal to the shoulder. Through the needle a straight guidewire was inserted after which the needle was removed. The catheter was introduced over the guidewire and guided forward $6 \mathrm{~cm}$ into the vein until the vena cava, while at the same time the guidewire was moved gently backwards. When the catheter was inserted completely and the guidewire removed, the catheter was filled with heparinised saline (100 IU heparin/ml saline). The catheter was secured at the entry point with two ligatures through the wings of the catheter and at the end of the catheter. At the back of the bird an end plate was secured. The bird was put back in its cage. With a string from endplate to swivel the broiler was tethered and the catheter was joined via a connecting tube to the swivel. The other end of the swivel was joined by a tube to the three way stop cock of the syringe in the infusion pump (continuous infusion of $100 \mathrm{IU}$ heparin/ml saline; $0.5 \mathrm{ml} / \mathrm{h}$ ). Total catheterization procedure took 25-30 min per bird.

\subsection{Blood sampling}

Blood was collected by sampling (the tether line) from the three way stop cock near the infusion pump. The first syringe hold mixed blood and saline but the second a pure blood sample (1.5 ml). The mixed blood was returned to the bird to minimize blood loss, and the tubing line was flushed with heparinized saline solution out of a third syringe. Blood $(1.5 \mathrm{ml})$ was sampled into tubes containing lithium heparin (Monovette $\Re$; Sarstedt). Blood samples were immediately stored on ice. Blood samples were centrifuged within $2 \mathrm{~h}$ at $3000 \mathrm{rpm}$ at $4 \mathrm{oC}$ during $10 \mathrm{~min}$. After centrifugation, plasma was stored at $-200 \mathrm{C}$ until analysis.

While the volume of blood is almost never a limitation in research with growing pigs, the blood volume of a broiler with a body weight of 1 to $2 \mathrm{~kg}$ restricts the volume and/or the number of blood samples that can be taken in order to prevent anaemia. However, on the other hand, an adequate number of 
samples of isotopic enriched plasma is needed in time to fit data on to the ${ }^{13} \mathrm{C}$ enrichment of $\mathrm{AA}$ in plasma with a double exponential model.

In studies with growing pigs using the same methodology $[4,5]$, one blood sample was taken before and up to 10 blood samples ( $4 \mathrm{ml}$ each) were taken from the jugular vein after administration of labelled $A A$ in the carotid vein. Data on the ${ }^{13} \mathrm{C}$ enrichment of these samples were used to fit a double exponential model to the time course after their administration.

Although for analysing only ${ }^{13} \mathrm{C}$ enrichment the volume of each sample was reduced to $1.5 \mathrm{ml}$, taking 11 blood samples within a short time period and planning to repeat this after a challenge within a few days is still a too demanding as it is recommended to take $<15 \%$ of total blood volume over a period of 3-4 weeks. With a very accurate record of the time of sampling and a reduction of the number of samples (after administration) to 8 in total, however, it appeared possible to adequately fit a double exponential model to the course of ${ }^{13} \mathrm{C} \mathrm{AA}$ enrichment in blood plasma accurately. The number of samples could be principally further lowered when instead of a bolus administration of labelled AA, labelled AA were administered continuously and ${ }^{13} \mathrm{C}$ enrichment of AA is fitted with a single exponential model. Although the latter method is preferred with regard to the blood volume sampled, this method is finally not preferred and incorporated for different reasons: a) both an infusion site and a sampling site was needed so catheters needed to be fitted and to remain functional in both wings of a bird, b) for two catheters from one bird a multi-channel swivel is needed, which was shown to be less functional, c) the labelled AA needed to be infused for some hours to reach and measure in a steady state condition for ${ }^{13} \mathrm{C}$ labelled $\mathrm{AA}$ resulting in a substantial higher amount of labelled $\mathrm{AA}$ required for the measurement ( $\sim 5$ times) and related costs, and $d$ ) the time needed to reach a steady state of ${ }^{13} \mathrm{C}$ labelled AA before samples can be taken was much longer ( 5 times) than when the bolus administration was used, resulting in more laborious and less efficient execution procedures.

\subsection{Analysis}

In each blood sample, ${ }^{13} \mathrm{C}$ enrichment was measured in plasma Glu, Gln, Gly, His, Ile, Leu, Lys, Met, Phe, Pro, Ser, Thr, Trp, Tyr and Val as ethyl chloroformate ester (ECF; Merck Schuchardt OHG) derivatives by GC-combustion-isotope ratio MS (Isotope Ratio MS, Delta V Advantage, Thermo Scientific; GC Trace Ultra, Thermo Scientific (column no. CP8982, VF-17ms 30m·0.25 mm, film $0.25 \mu \mathrm{m}$; Agilent Technologies); and combustion (Combustion III, Thermo Scientific), as adapted from Hueng [6].

Briefly, $20 \mu \mathrm{l}$ hydrogen chloride $(1 \mathrm{M}$ ) and $200 \mu$ l Dowex ion exchange resin (AG $50 \mathrm{~W}-\mathrm{X} 8 \mathrm{H}+\mathrm{form}$, 200-400 mesh; Dow Chemical Company) were added to $180 \mu \mathrm{l}$ plasma and eluted with $0.7 \mathrm{ml}$ ammonium hydroxide $(6 \mathrm{M})$ to isolate free plasma AA. The supernatant was evaporated with a centrifugal concentrator (Jouan RC 1022; Thermo Scientific) under vacuum at room temperature. Derivatisation was performed by adding $140 \mathrm{ml}$ ethanol-pyridine $(4: 1, \mathrm{v} / \mathrm{v})$ and $20 \mu \mathrm{l}$ ECF to the dry supernatant. Derivates were extracted by adding 4.200 $\mu$ l hexane-dichloromethane-ECF (50:50:1, by volume), and the supernatant was dried in a vial under $\mathrm{N}_{2}$ gas at room temperature. After dissolving in $50 \mu \mathrm{l}$ ethyl acetate, the sample was injected in triplicate into the GC. The ${ }^{13} \mathrm{C}$ enrichment of histidine could not always be successfully analysed due to high losses of histidine during the derivatisation step and for the analysis of the ${ }^{13} \mathrm{C}$ enrichment of Thr and Ser an additional derivatisation is required, the procedure not being implemented in the operating procedures of the lab involved.

\subsection{Calculations}

A mixture of $15 \mathrm{U}-{ }^{13} \mathrm{C}$-labelled AA (97-99 atom percent ${ }^{13} \mathrm{C}$; Cambridge Isotope Laboratories) was administered. The composition of this mixture (mg/g saline) was as follows: $0.040 \mathrm{~L}-\mathrm{Glu}, 0.355 \mathrm{~L}-\mathrm{Gln}$, 0.071 L-Gly, 0.036 L-His, 0.042 L-Ile, 0.057 L-Leu, 0.260 L-Lys, 0.034 L-Met, 0.058 L-Phe, 0.082 LPro, $0.108 \mathrm{~L}-\mathrm{Ser}, 0.159 \mathrm{~L}-\mathrm{Thr}, 0.019 \mathrm{~L}-\mathrm{Trp}, 0.093 \mathrm{~L}-\mathrm{Ty}$ r and $0.046 \mathrm{~L}-\mathrm{Val}$. This composition was based on data of plasma AA concentration in broilers from literature (as no recent data on broiler $A A$ concentrations from own studies were known) aiming to increase ${ }^{13} \mathrm{C}$ enrichment in plasma by not more than $4.5 \%$ and taking experiences from the pig studies concerning loss of ${ }^{13} \mathrm{C}$-enrichment analysis of Ile, Met, Phe and Tyr into account. The mixture was injected via the three way stop cock as 
a bolus ( $1 \mathrm{ml} / \mathrm{kg}$ body weight) in about 4 seconds time, after which tubing line and catheter were flushed with $3 \mathrm{ml}$ heparinized saline solution.

Blood samples were collected at about $10 \mathrm{~min}$ before the bolus administration of the $\mathrm{U}-{ }^{13} \mathrm{C}-$ labelled AA mixture and at $1,3,7,11,15,30$ and 60 min after administration.

${ }^{13} \mathrm{C}$ enrichment in plasma $A A$ was expressed as the tracer:tracee ratio (TTR) [4]. To calculate a change in the TTR in time, for each AA, the background enrichment (obtained from the plasma sample taken before the administration of the $\mathrm{U}-{ }^{13} \mathrm{C}$-labelled AA mixture) was subtracted from ${ }^{13} \mathrm{C}$ enrichment in samples after administration.

The ILR of AA from plasma was calculated from the change in the ${ }^{13} \mathrm{C}$ enrichment of plasma $\mathrm{AA}$ after the intravenously administered bolus of $U-{ }^{13} \mathrm{C}$-labelled $\mathrm{AA}$ using the model and calculations as originally described [7]. The following assumptions were made: there is a physiological steady state during the measurement, i.e. a constant size of the plasma AA pool, so that the inflow of AA into the plasma pool equals the outflow from the plasma pool [2]; the tracer transfers along with the tracee between compartments with a constant fractional rate [2]; the ILR for an AA occurs as an output from the plasma pool, and only by the incorporation of the $A A$ into synthesised protein or by the loss of the AA via oxidation [8]. Finally, once the tracer has entered the body protein pool, there is no recycling of the tracer into the plasma pool, as the whole-body protein pool is a large pool with a low turnover rate compared with the plasma pool [2]. A double exponential model was fitted to the ${ }^{13} \mathrm{C}$ enrichment of individual plasma AA after the administration of the bolus:

$E(t)=a_{1} \exp \left(b_{1} t\right)+a_{2} \exp \left(b_{2} t\right)$,

where $E(t)$ is the predicted ${ }^{13} \mathrm{C}$ enrichment in plasma $A A(T T R)$ at time $t$ ( $\left.m i n\right)$ and $a_{1}, b_{1}, a_{2}$ and $b_{2}$ are parameter estimates from which the ILR ( $\mu \mathrm{mol} / \mathrm{kg} \mathrm{BW}$ per $\mathrm{h}$ ) is calculated:

$\operatorname{ILR}=d /\left(a_{1} / b_{1}+a_{2} / b_{2}\right) * 60$,

where $d$ is the dose of the administered $U-{ }^{13} \mathrm{C}$-labelled $A A(\mu \mathrm{mol} / \mathrm{kg} \mathrm{BW})$.

For each AA and broiler, the pool size, i.e. the amount of AA in the plasma pool ( $\mu \mathrm{mol} / \mathrm{kg} \mathrm{BW})$, is calculated as:

Pool size $=d /\left(a_{1}+a_{2}\right)$. 


\section{Results}

Five broilers were fitted with two catheters and one bird with just one catheter at a weight of on average $1502 \mathrm{~g}$ (minimum 1401, maximum $1602 \mathrm{~g}$ ). The next day bolus administration of labelled AA was conducted and of all 6 birds almost all planned blood samples could be taken.

The day before surgery the feed intake of the broilers averaged $111 \mathrm{~g}$ (minimum: 104, maximum: 117) and at the day of surgery the feed intake averaged $112 \mathrm{~g}$ (minimum: 94, maximum: 133). The next day when the labelled AA were administered, the feed intake averaged $91 \mathrm{~g}$ with a much lower intake of birds $2(46 \mathrm{~g})$ and $4(53 \mathrm{~g})$.

After ${ }^{13} \mathrm{C}$ bolus administration blood samples could be taken according plan, except in broiler 1 of which one sample was missed and in broiler 4 in which two samples were missed.

For most AA a double exponential model could be fitted for the decay of the ${ }^{13} \mathrm{C}$ enrichment after the administration of the bolus. As an example in Figure 2 the fitted curves for bird 5 were shown.

Because two samples were missing, the decay of ${ }^{13} \mathrm{C}$ enrichment could not be fitted for some $A A$ in bird 4. In some birds the decay in enrichment could not be fitted for some $A A$; this concerned mostly His and occasionally GIn, Ile, Ser and Val. There was a large difference in ILR between AA (Figure 3), ranging from 283 for Trp to $8175 \mu \mathrm{mol} / \mathrm{kg}$ BW per h for Gln. 
TTR 5: G Iu

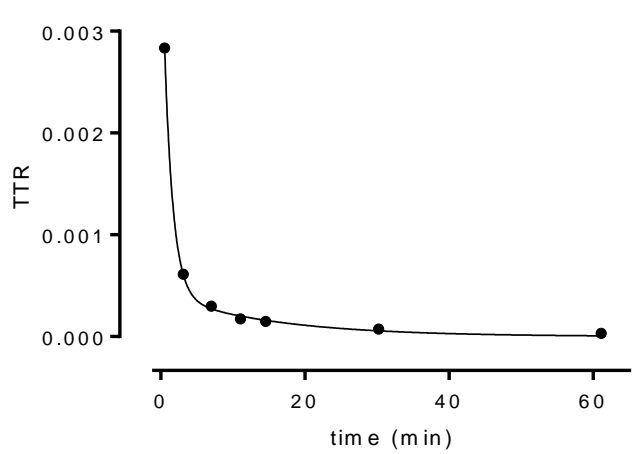

TTR 5: G Iy

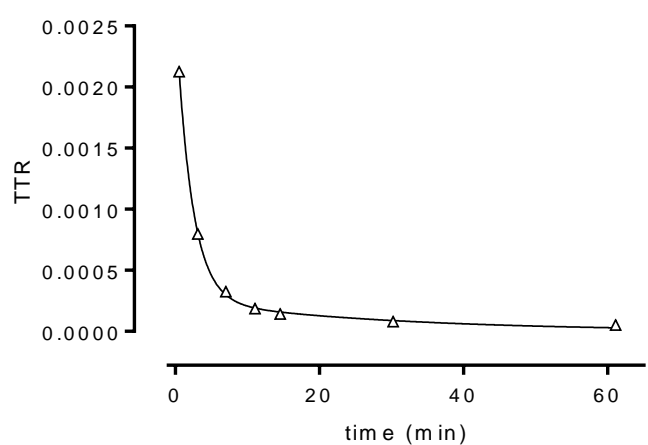

TTR 5 : Ile

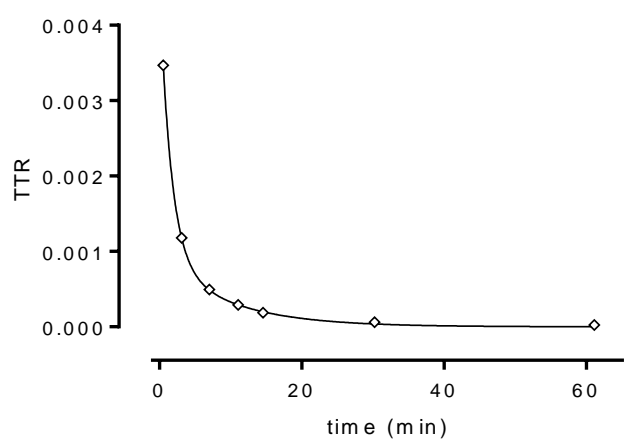

TTR 5: Lys

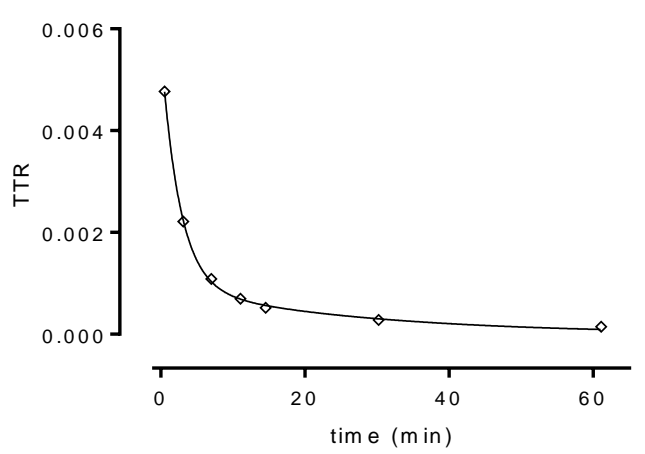

TTR 5: G In

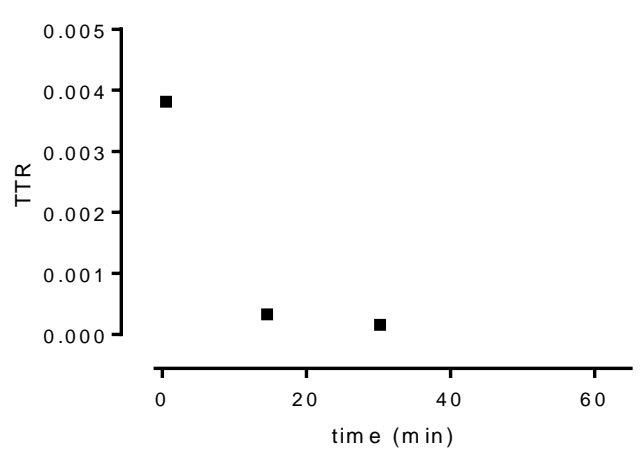

TTR $5: \mathrm{H}$ is

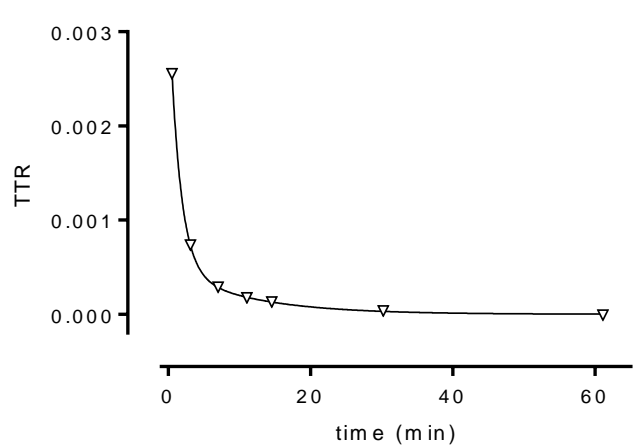

TTR 5: Leu

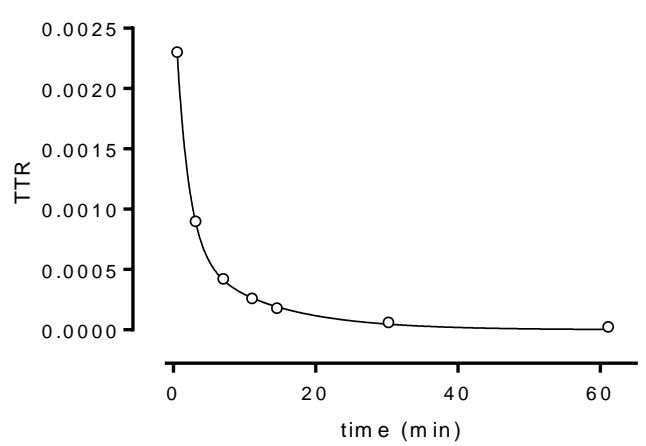

TTR 5: Met

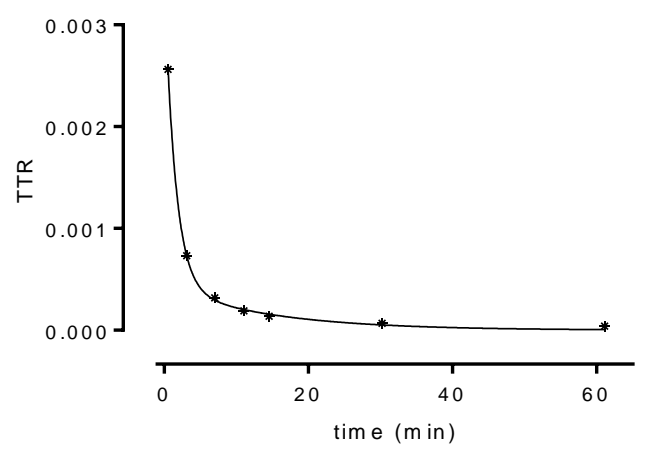


TTR 5: Phe

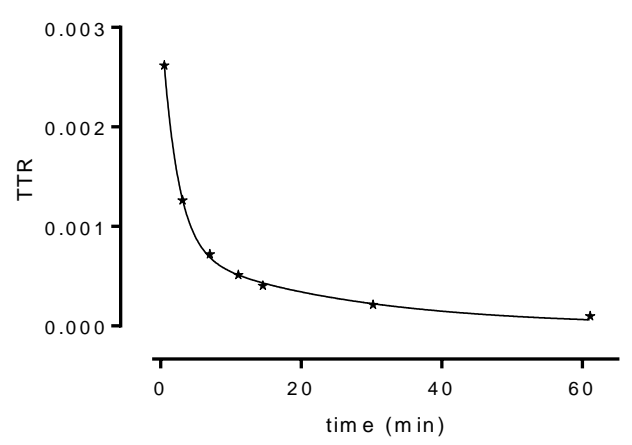

TTR 5: Ser

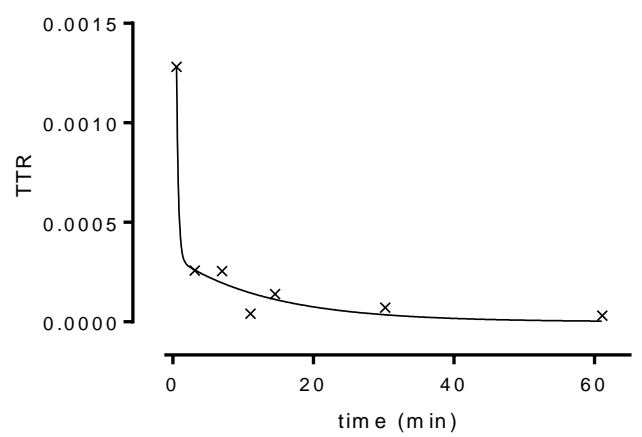

TTR 5 : Trp

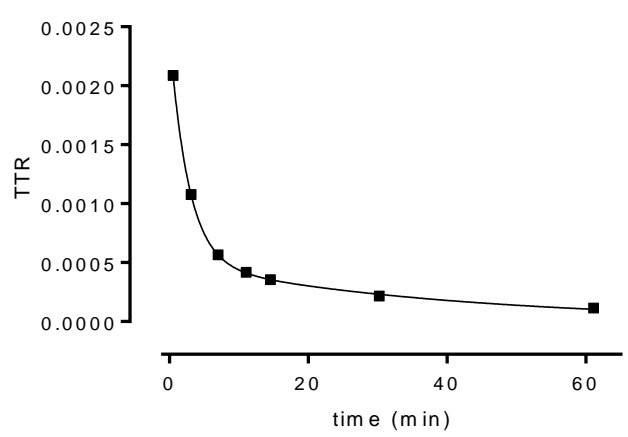

TTR 5: Val

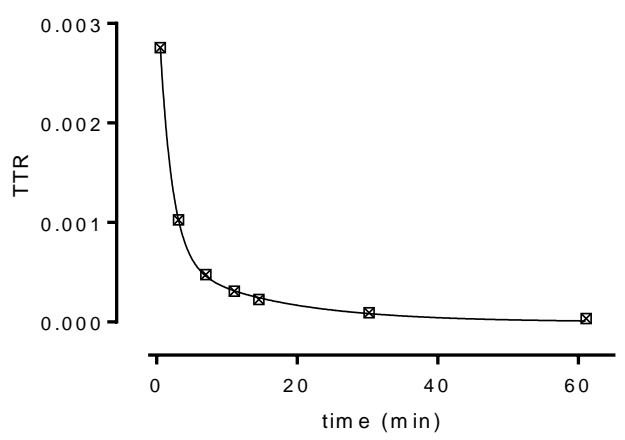

TTR 5: Pro

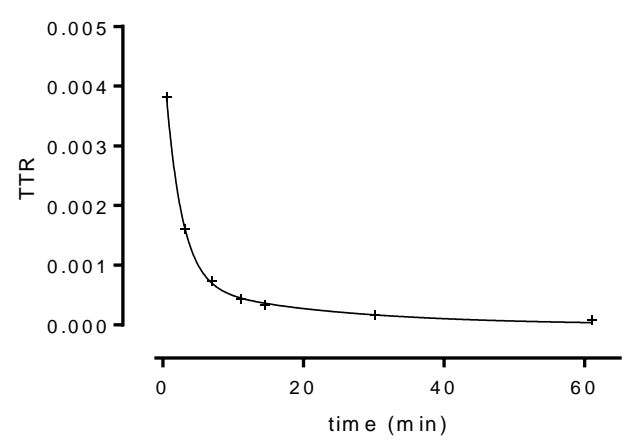

T TR 5: Th r

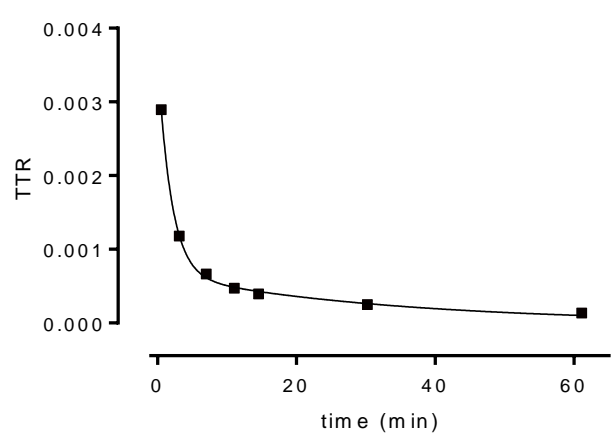

TTR 5 : Tyr

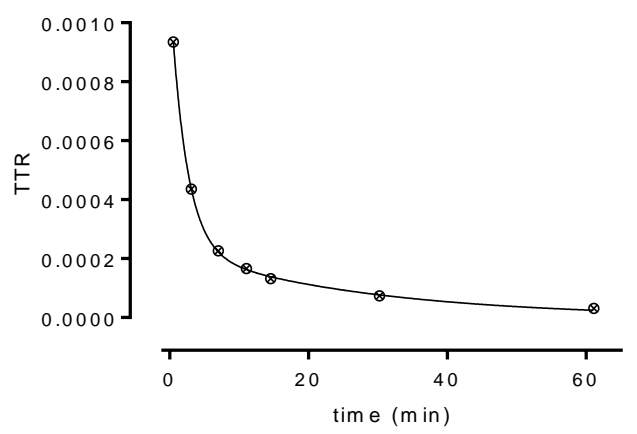

Figure 2 Fitted decay in ${ }^{13} \mathrm{C}$ enrichment in 15 amino acids in blood plasma of broilers after bolus infusion of a mixture of ${ }^{13} \mathrm{C}$ amino acids (example bird 5). 


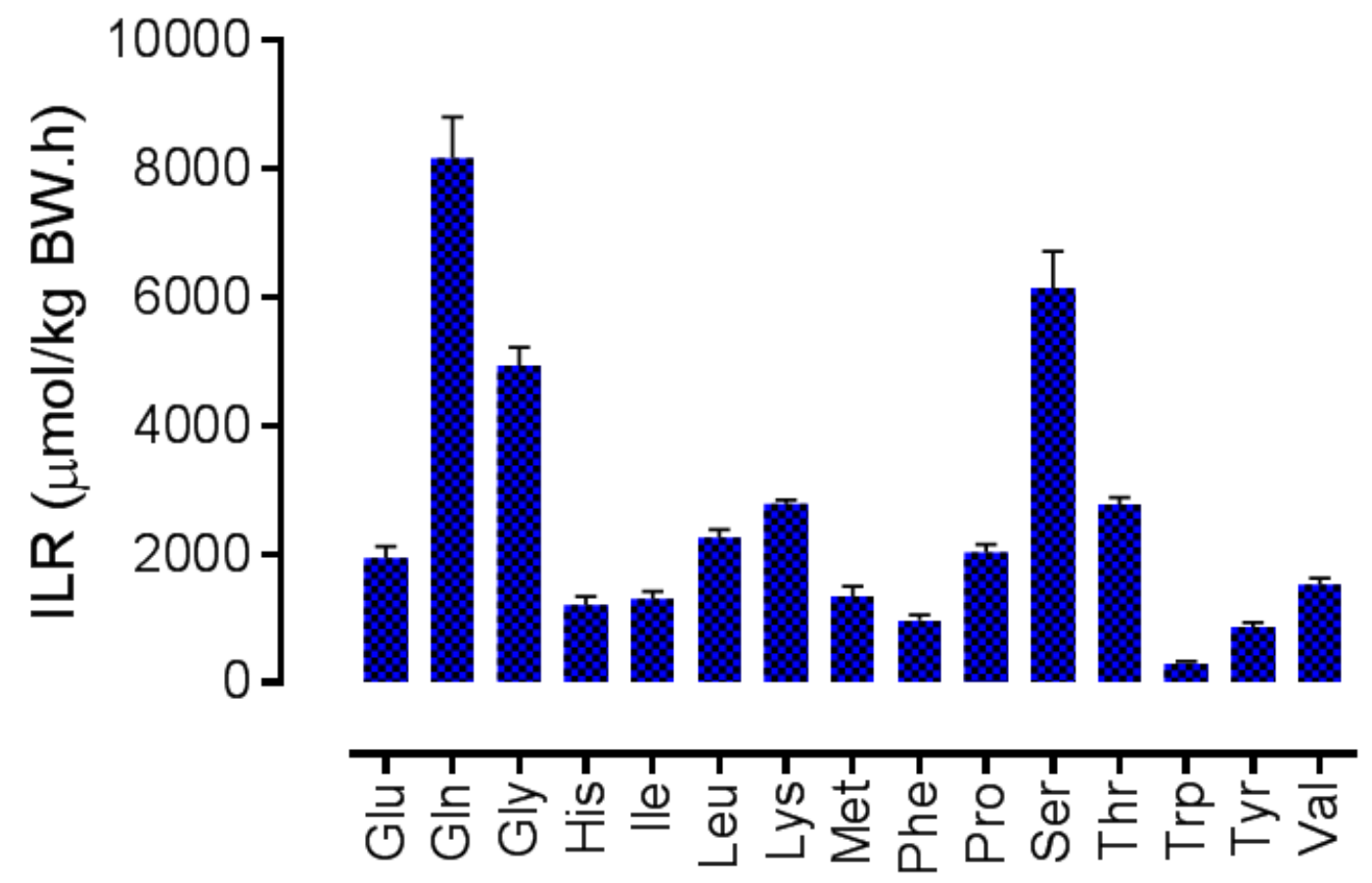

Figure 3 The irreversible loss rates (ILR) of 15 AA measured in broilers (average \pm SEM, $n=6$ ). 


\section{Discussion}

Some critical technical points concerning the translation of the technique of measuring ILR AA in growing pigs to broilers were encountered during the transition to and evaluation of the technique in broilers. Bolus administration of labelled AA with a very accurate record of the time of blood sampling and collection of not more than 8 blood samples after bolus ${ }^{13} \mathrm{C} \mathrm{AA}$ administration, allows fitting of the decay of the ${ }^{13} \mathrm{C}$ enrichment with a double exponential model and subsequently calculation of ILR and pool size of Glu, GIn, Gly, Ile, Leu, Lys, Met, Phe, Pro, Ser, Thr, Trp, Tyr and Val in broilers. Just as in pigs $[4,5]$, analysis of the ${ }^{13} \mathrm{C}$ enrichment of His was difficult due to high losses of His during derivatisation and consequently fitting of the decay of ${ }^{13} \mathrm{C}$ enrichment of His was not always possible. Also, occasionally fitting of the decay of enrichment with the selected model for some other AA was not possible, the reason for this being unknown.

The way of taking frequent blood samples in birds, however, can be improved further in relation to e.g. fixing the catheter on the bird (as a kind of jacket), its junction to the swivel and the construction of the swivel in the cage.

Differences in ILR and pool size between AA will be further considered when ILR and pool size of broilers fed protein adequate and restricted diets can be compared or when data will be available on ILR and pool sizes of AA of birds before and after an immune challenge. So far, it seems that the ILR of all essential AA (Ile, Leu, Lys, Met, Phe, Tyr and Val) except for Trp is higher is broilers than in pigs [4], which may be related to the higher relative protein accretion rates in broilers compared to pigs. 


\section{$5 \quad$ Literature}

1. Kampman-van de Hoek, E., Impact of health status on amino acid requirements of growing pigs : towards feeding strategies for farms differing in health status. 2015, Wageningen University: Wageningen.

2. Waterlow, J.C., Protein turnover. Protein Turnover. 2006. 1-301.

3. De Jong, I.C., et al., Determination of the circadian rhythm in plasma corticosterone and catecholamine concentrations in growing broiler breeders using intravenous cannulation. Physiology and Behavior, 2001. 74(3): p. 299-304.

4. Kampman-van De Hoek, E., et al., Induced lung inflammation and dietary protein supply affect nitrogen retention and amino acid metabolism in growing pigs. British Journal of Nutrition, 2015. 113(3): p. 414-425.

5. Kampman-van de Hoek, E., et al., Dietary amino acid deficiency reduces the utilization of amino acids for growth in growing pigs after a period of poor health. Journal of Nutrition, 2016. 146(1): p. 51-58.

6. Huang, L., et al., Lysine requirement of the enterally fed term infant in the first month of life. American Journal of Clinical Nutrition, 2011. 94(6): p. 1496-1503.

7. Holtrop, G., H. Lapierre, and G.E. Lobley, Modelling transport of amino acids into the red blood cells of sheep. Journal of Agricultural Science, 2004. 142(5): p. 577-588.

8. Reeds, P.J., et al., Protein turnover in growing pigs. Effects of age and food intake. British Journal of Nutrition, 1980. 43(3): p. 445-455. 


\section{Appendix 1}

The ILR and pool size of 15 AA determined simultaneously in 6 broilers.

\begin{tabular}{|c|c|c|c|c|c|c|c|c|c|}
\hline \multicolumn{10}{|c|}{ ILR (umol/kg BW.h) } \\
\hline broiler & $\mathrm{BW}(\mathrm{kg})$ & Glu & Gln & Gly & His & Ile & Leu & Lys & Met \\
\hline 1 & 1453 & 2676 & & 5330 & & & 2314 & 2828 & 1945 \\
\hline 2 & 1401 & 2054 & 9444 & 4818 & & 1216 & 2100 & 2638 & 1130 \\
\hline 3 & 1583 & 2033 & 7492 & 5073 & 1002 & 1601 & 2680 & 2890 & 1278 \\
\hline 4 & 1602 & 1941 & & 5957 & & & & 2869 & \\
\hline 5 & 1485 & 1530 & & 4601 & 1456 & 1339 & 2286 & 2924 & 1281 \\
\hline 6 & 1490 & 1443 & 7588 & 3864 & 1196 & 1068 & 1951 & 2616 & 1117 \\
\hline avg & 1502 & 1946 & 8175 & 4941 & 1218 & 1306 & 2266 & 2794 & 1350 \\
\hline std & 77 & 442 & 1100 & 706 & 228 & 226 & 274 & 133 & 342 \\
\hline \multicolumn{10}{|c|}{ ILR (umol/kg BW.h) } \\
\hline broiler & $\mathrm{BW}(\mathrm{kg})$ & & Phe & Pro & Ser & Thr & Trp & Tyr & Val \\
\hline 1 & 1453 & & 1298 & 2375 & 5950 & 2762 & 380 & 947 & \\
\hline 2 & 1401 & & 869 & 1924 & 7034 & 2634 & 242 & 806 & 1384 \\
\hline 3 & 1583 & & 1021 & 2208 & 7743 & 3188 & 320 & 1105 & 1783 \\
\hline 4 & 1602 & & & 1632 & 4545 & 2531 & 429 & & \\
\hline 5 & 1485 & & 884 & 1824 & & 2983 & 232 & 773 & 1611 \\
\hline 6 & 1490 & & 809 & 2236 & 5484 & 2606 & 240 & 731 & 1348 \\
\hline avg & 1502 & & 976 & 2033 & 6151 & 2784 & 307 & 872 & 1532 \\
\hline std & 77 & & 196 & 285 & 1263 & 253 & 83 & 153 & 204 \\
\hline & & & & & & & & & \\
\hline & & & & & & & & & \\
\hline \multicolumn{10}{|c|}{ pool size (umol/kg BW) } \\
\hline broiler & $\mathrm{BW}(\mathrm{kg})$ & Glu & Gln & Gly & His & Ile & Leu & Lys & Met \\
\hline 1 & 1453 & 180 & & 444 & & & 83 & 235 & 122 \\
\hline 2 & 1401 & 90 & 780 & 280 & & 51 & 107 & 263 & 66 \\
\hline 3 & 1583 & 82 & 782 & 383 & 82 & 80 & 185 & 242 & 97 \\
\hline 4 & 1602 & 393 & & 883 & & & & 650 & \\
\hline 5 & 1485 & 65 & & 362 & 68 & 71 & 153 & 319 & 66 \\
\hline 6 & 1490 & 37 & 337 & 151 & 43 & 27 & 60 & 116 & 38 \\
\hline avg & 1502 & 141 & 633 & 417 & 65 & 57 & 117 & 304 & 78 \\
\hline std & 77 & 132 & 256 & 250 & 19 & 24 & 51 & 182 & 32 \\
\hline \multicolumn{10}{|c|}{ pool size (umol/kg BW) } \\
\hline broiler & $\mathrm{BW}(\mathrm{kg})$ & & Phe & Pro & Ser & Thr & Trp & Tyr & Val \\
\hline 1 & 1453 & & 80 & 216 & 817 & 478 & 16 & 24 & \\
\hline 2 & 1401 & & 79 & 99 & 485 & 313 & 30 & 127 & 55 \\
\hline 3 & 1583 & & 86 & 230 & 695 & 576 & 36 & 180 & 89 \\
\hline 4 & 1602 & & & 281 & 2205 & 1264 & 51 & & \\
\hline 5 & 1485 & & 114 & 157 & & 377 & 39 & 96 & 113 \\
\hline 6 & 1490 & & 35 & 99 & 250 & 179 & 18 & 74 & 40 \\
\hline avg & 1502 & & 79 & 180 & 890 & 531 & 32 & 100 & 74 \\
\hline std & 77 & & 28 & 74 & 766 & 384 & 13 & 58 & 33 \\
\hline
\end{tabular}




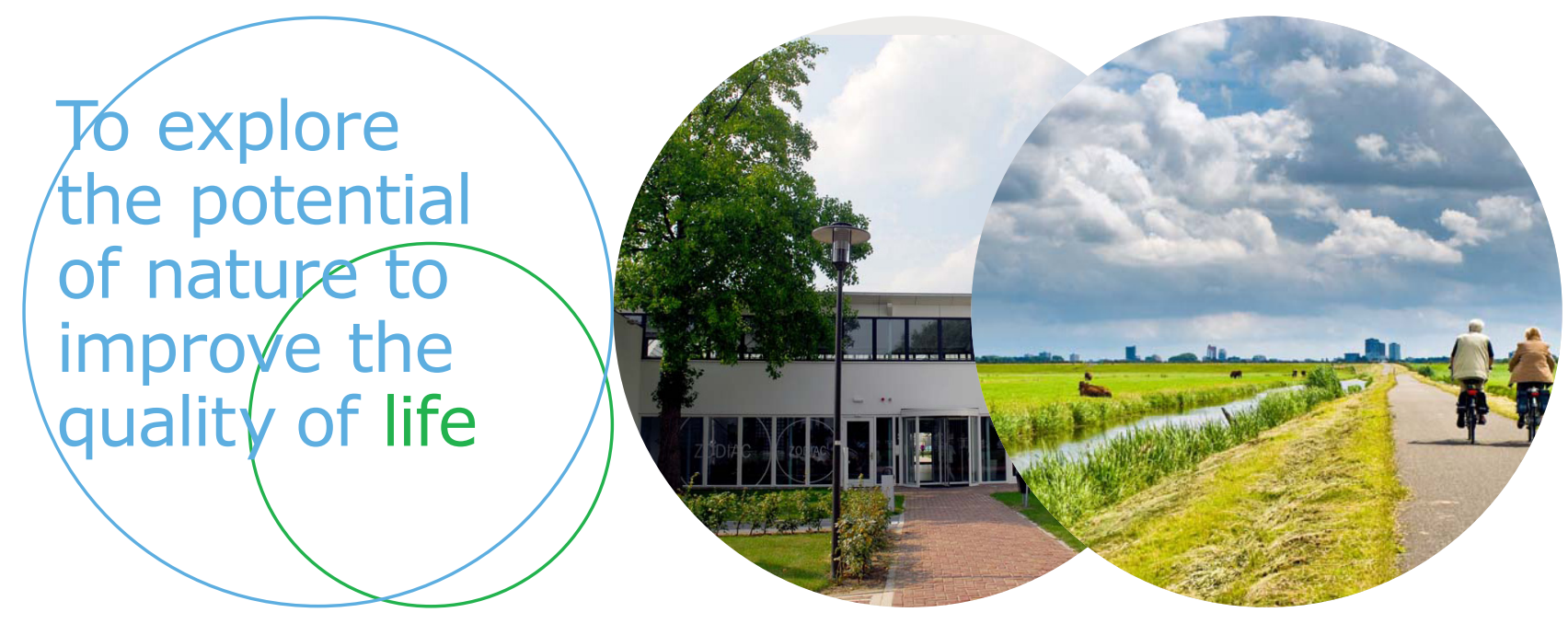

Wageningen Livestock Research P.O. Box 338

$6700 \mathrm{AH}$ Wageningen

The Netherlands

T +31 (0)317483953

E info.livestockresearch@wur.nl

www.wur.nl/livestock-research

Wageningen Livestock Research creates science based solutions for a sustainable and profitable livestock sector. Together with our clients, we integrate scientific knowledge and practical experience to develop livestock concepts for future generations.

Wageningen Livestock Research is part of Wageningen University \& Research. Together we work on the mission: 'To explore the potential of nature to improve the quality of life'. A staff of 6,500 and 10,000 students from over 100 countries are working worldwide in the domain of healthy food and living environment for governments and the business community-at-large. The strength of Wageningen University \& Research lies in its ability to join the forces of specialised research institutes and the university. It also lies in the combined efforts of the various fields of natural and social sciences. This union of expertise leads to scientific breakthroughs that can quickly be put into practice and be incorporated into education. This is the Wageningen Approach. 